\title{
Airspace size in lungs of lifelong non-smokers: effect of age and sex
}

\author{
Marion Gillooly, David Lamb
}

\begin{abstract}
Background Emphysema is defined as the abnormal enlargement of airspaces distal to the terminal bronchiole, but the limits of normality of airspace size have never been defined. The aims of the study were to examine the effects of age and sex on airspace size in non-smokers and to define the limits of normal airspace size. Methods Airspace size was measured in terms of airspace wall surface area per unit volume of lung tissue (AWUV). AWUV was measured on histological sections of lung tissue with an automated scanning system, the fast interval processor. Thirty eight lifelong non-smokers were studied, 15 male and 23 female, with an age range of 21-93 years. Macroscopic emphysema was assessed semi-quantitatively on the midsagittal slice of each lung specimen.
\end{abstract}

Results The relation between mean AWUV and age was negative $(r=$ $-0 \cdot 78)$. This relation was linear, and the $95 \%$ prediction limits of its regression line were used as the limits of normality of AWUV in this sample. The AWUV-age relationship was similar in the men and women studied. Localised areas of macroscopic emphysema were found in three specimens whose mean AWUV measurements were within the normal range.

Conclusions There is a normal increase in airspace size associated with advancing age in adult lungs. The limits of normal AWUV between ages 21 and 93 years have been defined, and it is proposed that lungs with a mean AWUV below the $95 \%$ prediction limit should be considered as having emphysema.

(Thorax 1993;48:39-43)

Emphysema is defined as "a condition of the lung characterised by abnormal, permanent enlargement of airspaces distal to the terminal bronchiole, accompanied by destruction of their walls and without obvious fibrosis." "By this definition emphysema is an abnormal increase in airspace size. The limits of normality of airspace size in adults have never been defined, however, and as the shape and structure of the lungs appear to change with advancing age ${ }^{2}$ "normal" airspace size is unlikely to remain the same throughout adult life. The need to establish the normal range of airspace size with age and sex was recognised at a Ciba symposium in $1958 .^{3}$ This problem has not yet been solved, however.

Most studies of emphysema have been based on observations made on paper mounted sections of whole lungs, or on lung slices in fixative, with airspaces larger than $1 \mathrm{~mm}$ in diameter considered to be emphysematous. ${ }^{4-6}$ Detailed studies of human lungs have shown that, although there is variation in airspace size, the average diameter is around 250 $\mu \mathrm{m} .{ }^{78}$ Clearly a substantial amount (as much as three quarters) of the airspace wall surface area must have been lost before the airspaces become visible macroscopically. This prohibits the use of macroscopic techniques to identify and quantify early emphysema.

Several studies have shown cigarette smoking and age to be major factors that influence the incidence of macroscopic emphysema. ${ }^{9-12}$ Macroscopic emphysema has been found to occur more frequently and to become more severe with age in smokers. ${ }^{13-19}$ The effects of smoking and age on the lung are closely linked because the effect of smoking is a cumulative one, which therefore increases with advancing age. To assess the influence of age on airspace size, a group of non-smokers must be studied. Our aims in this study were to observe the effects of age and sex on airspace size in a group of 38 lifelong non-smokers, and to define the limits of normal airspace size, which would allow the diagnosis of emphysema to be based on its definition.

\section{Methods}

THE SAMPLE

The sample consisted of lungs or lobes from 38 individuals, 15 of whom were male and 23 female. All were lifelong non-smokers. Their ages ranged from 21 to 93 years. Sixteen specimens were lungs obtained at necropsy and 22 were lobes from surgical resection.

\section{SMOKING HISTORIES}

Reliable smoking histories are difficult to obtain, especially when the sample includes necropsy specimens. Smoking histories for the surgical cases in this study, however, were obtained from clinical records, and those from the necropsy cases were recorded at interviews with relatives at the time of death. Individuals were included in the study group only if they were described in the records as "lifelong non-smokers."

NECROPSY SPECIMENS

The lungs taken at necropsy that we used in 
this study were also included in a study of the distribution of airspace size from apex to base of the lung, ${ }^{20}$ and this is reflected in the sampling design used. Lungs were removed at necropsy (one lung from each subject) and immediately inflated with $10 \%$ buffered formalin at a pressure of $25 \mathrm{~cm} \mathrm{H}_{2} \mathrm{O}$ and then fixed in $10 \%$ buffered formalin for at least 24 hours. Fixation was not carried out by continuous perfusion as this proved impractical for the lobectomy specimens (see below) where only the cut ends of the segmental or subsegmental bronchi were present. After complete fixation the lungs were cut into $1 \mathrm{~cm}$ parasagittal slices. The midsagittal slice from each lung was divided into six zones, three from the upper and three from the lower lobe, according to the apex to base height of the lobes. (In right lung specimens the middle lobe was considered as part of the upper lobe.) Two $2 \times 2 \mathrm{~cm}$ blocks were cut at random from each zone (a total of 12 blocks from each lung)-see figure 1. Tissue blocks were processed and embedded in glycol methacrylate resin and a $3 \mu \mathrm{m}$ section was cut from each block and stained with haematoxylin and eosin.

\section{LOBES OBTAINED DURING SURGERY}

We collected 22 lobes that had been surgically removed as treatment for small peripheral lesions. The diagnoses in these cases are shown in table 1. The lobes were inflated, fixed, and sliced in the same way as the lungs obtained at necropsy (see above). Random blocks were selected from the lateral two subpleural slices. This was in keeping with the sampling design used in a previous study of the structure-function relationships in the lung, where the most alveolated portion of the lung was required..$^{21}$ At least six blocks were cut from each lobe. As with the lungs obtained at necropsy, a $3 \mu \mathrm{m}$ section was cut from each block and stained with haematoxylin and eosin.

\section{THE FAST INTERVAL PROCESSOR}

The fast interval processor is an automated scanning device ${ }^{22} 23$ that works on the same principle as the mean linear intercept $(\mathrm{Lm})$

\footnotetext{
Figure 1 Diagram representing the sampling procedure used on the midsagittal slice of post mortem lungs. The upper and lower lobes were divided into three zones based on the apex to base height of the lobe, and two random $2 \times 2 \mathrm{~cm}$ blocks were cut from each zone.
}

Table 1 Summary of the diagnoses of lesions in the lobes removed at surgery

\begin{tabular}{ll}
\hline & No of lobes \\
\hline Primary malignant tumour & 5 \\
Secondary tumour & 5 \\
Carcinoid tumour & 5 \\
Focal congenital lesion & 3 \\
Focal inflammatory lesion & 2 \\
Benign tumour & 1 \\
Hamartoma & 1 \\
\hline
\end{tabular}

technique, whereby intercepts between alveolar walls and a test line are counted. The fast interval processor uses as the "test line" a photosensitive electronic scanner that recognises the difference in optical density between stained tissue and unstained background on histological sections. An area of $121 \mathrm{~mm}^{2}$ is scanned on each section, and the intercept total from each scan is used to calculate $\mathrm{Lm}$. The airspace wall surface area per unit volume of lung tissue (AWUV) is derived from $\mathrm{Lm}$ by using the equation AWUV $=2 / \mathrm{Lm}^{23}$ AWUV is inversely related to airspace size. In this study the mean AWUV was calculated for each specimen, and this value was plotted against the age of the subject.

MACROSCOPIC ASSESSMENT OF EMPHYSEMA

The midsagittal slice of each lung or lobe was examined by an experienced pathologist (DL) and the extent and types of emphysema were recorded as follows:

Where centriacinar emphysema was present the number of the individual lesions was noted. Panacinar emphysema was described as mild, moderate, or severe ${ }^{3}$ and the percentage of the lobe area affected was measured by tracing the lobe outline on to a transparent plastic sheet and then tracing the areas of panacinar emphysema on to the same sheet. The areas of the tracings were measured with graph paper, and the percentage of the area of the midsagittal slice showing panacinar emphysema was calculated, as were percentages showing other forms of macroscopic emphysema, such as scar, paraseptal, or bullous emphysema.

\section{ANALYSIS OF THE DATA}

The Spearman correlation coefficient was calculated for the relationship between AWUV and age. The regression equation for the line that best fitted the AWUV-age relationship and the $95 \%$ prediction limits of this line were also calculated. ${ }^{24}$

The regression equations for AWUV against age in the men and in the women of the sample were calculated, and analysis of variance of the regressions was used to examine sex differences in the AWUV-age relationship..$^{25}$

\section{Results}

A significantly negative relationship was found between AWUV and age in the 38 non-smokers studied $(\mathrm{r}=-0.78, \mathrm{p}<0.001$ ) (fig 2). This implies that alveolar wall surface 


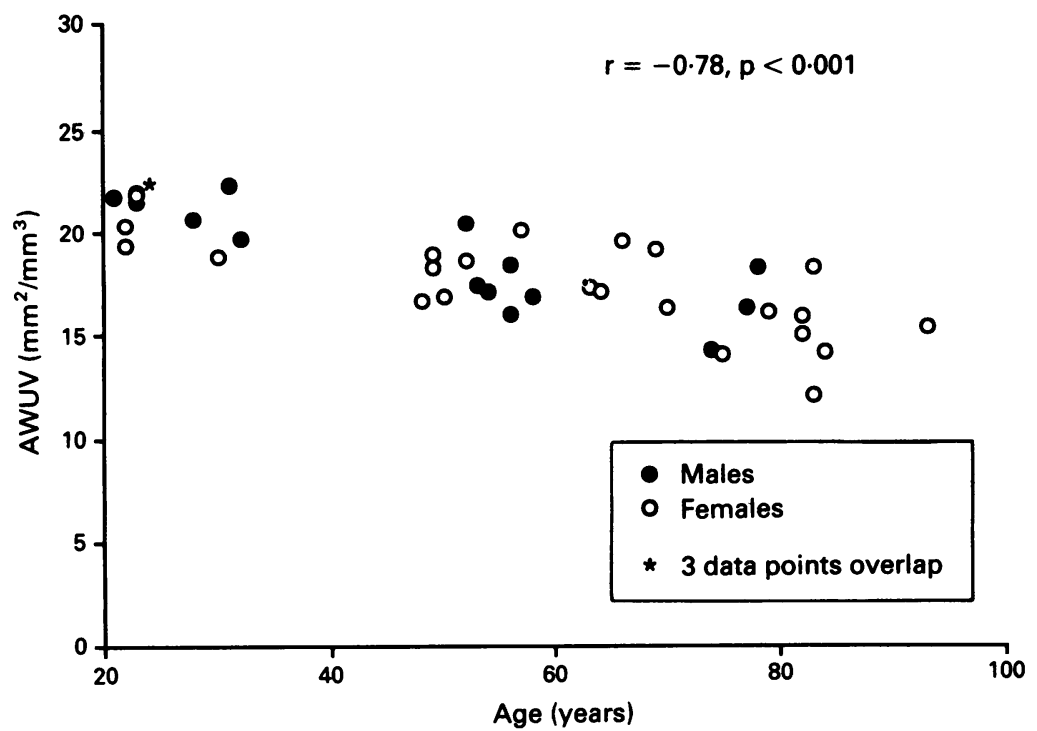

Figure 2 Mean airspace wall surface area per unit volume of lung tissue (AWUV) for each case plotted against age, with the correlation coefficient for the AWUV-age relationship. This graph illustrates the negative relationship between AWUV and age in this sample, and also shows that there were no sex differences in this relationship.

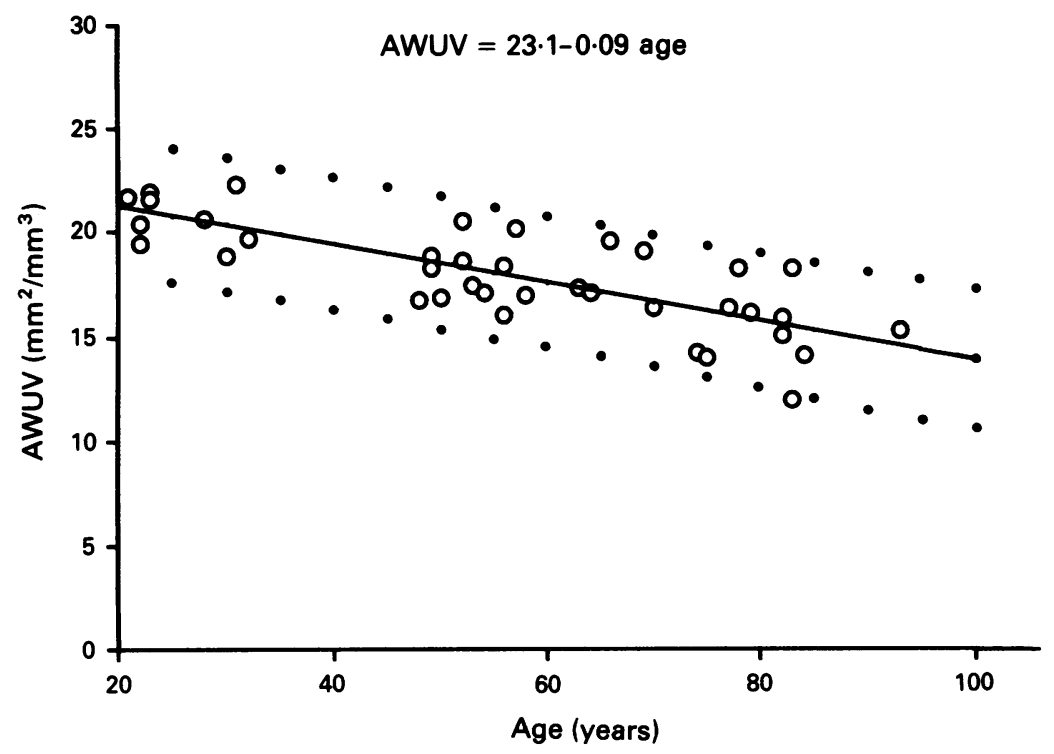

Figure 3 Mean airspace wall surface area per unit volume of lung tissue ( $A W U V$ ) for each case plotted against age, with the regression line for these points and its $95 \%$ prediction limits shown. The prediction limits have been used to supply a range of normal values for any age in this sample. The equation shown is the regression equation for the relationship between $A W U V$ and age.

area is reduced with increasing age (that is, airspace size is increased with age).

The regression line of AWUV and age and its $95 \%$ prediction limits were used to predict the range of normal mean AWUV values for any age in the sample (fig 3). The regression equation for AWUV and age was AWUV = 23.1-0.09AGE. The lower 95\% prediction limits of AWUV ranged from 17.99 to 11.54 $\mathrm{mm}^{2} / \mathrm{mm}^{3}$ over the age range $20-90$. Examples of the lower limits of normal mean AWUV are given in table 2.

There were no sex differences in the relationship between AWUV and age (fig 2).

Table 3 shows the age, sex, specimen description, and mean AWUV value for each of the 38 subjects.
Table 2 Examples of values for airspace wall surface area per unit volume of lung tissue $(A W U V)$ representing the lower limit of normality

\begin{tabular}{ll}
\hline $\begin{array}{l}\text { Age } \\
(y)\end{array}$ & $\begin{array}{l}\text { AMUV } \\
\left(\mathrm{mm}^{2} / \mathrm{mm}^{3}\right)\end{array}$ \\
\hline 20 & 17.99 \\
25 & 17.56 \\
30 & 17.12 \\
35 & 16.68 \\
40 & 16.24 \\
45 & 15.79 \\
50 & 15.33 \\
55 & 14.87 \\
60 & 14.41 \\
65 & 13.94 \\
70 & 13.47 \\
75 & 13.00 \\
80 & 12.52 \\
85 & 12.03 \\
90 & 11.54 \\
\hline
\end{tabular}

Evidence of macroscopic emphysema was found in only three of these non-smokers (1)-an 84 year old with nine centriancinar lesions in the upper lobe; (2) a 75 year old with six centriacinar lesions in the upper lobe; (3) a 77 year old with mild panacinar emphysema that occupied $10 \%$ of the upper lobe.

\section{Discussion}

Definitions of emphysema include the phrases "abnormal permanent enlargement of airspaces distal to the terminal bronchiole"1 and "increase beyond the normal in the size of air spaces distal to the terminal bronchiole." ${ }^{3}$ To apply these definitions we must have quantitative data on what is considered normal airspace size.

In this paper we have presented quantitative data on 38 lifelong non-smokers and shown that there is a decline in AWUV with age and a corresponding increase in airspace size. This will permit diagnosis and assessment of emphysema in quantitative terms in future if it is accepted that the changes with age described are normal and that only patients with AWUV values lying below the $95 \%$ prediction limit are abnormal.

The techniques used in this investigation provide data for AWUV values that are accurate and reproducible in terms of our methods. We have avoided much of the histological artefact of processing and section cutting by using glycol methacrylate as the embedding medium for our sections, ${ }^{26}$ but we cannot avoid a certain degree of shrinkage by the process of fixation itself. The fast interval processor technique has advantages and disadvantages, and may give absolute values that differ from other interactive or automated techniques. ${ }^{23}$ This does not affect the validity of our results in relation to age and AWUV.

THE USE OF SINGLE LOBES AS REPRESENTATIVE OF A LUNG

The samples studied here included 22 single lobes obtained by surgical resection. Apex to base variations in alveolar dimensions in upright lungs have been found in experiments using dogs. ${ }^{27}$ The potential size of the alveoli was not, however, found to vary from apex to base, because when the animals were supine the apical and basal alveoli were of the same 
Table 3 Sex, specimen type, age, and mean airspace well surface area per unit volume (AWUV) for all the subjects, listed in ascending order of age

\begin{tabular}{|c|c|c|c|c|c|c|c|c|c|}
\hline \multicolumn{5}{|c|}{ Necropsy specimens } & \multicolumn{5}{|c|}{ Biopsy specimens } \\
\hline $\begin{array}{l}\text { Case } \\
\text { No }\end{array}$ & Sex & $\begin{array}{l}\text { Specimen } \\
\text { type }\end{array}$ & $\begin{array}{l}\text { Age } \\
(y)\end{array}$ & $\begin{array}{l}A W U V \\
\left(\mathrm{~mm}^{2} / \mathrm{mm}^{3}\right)\end{array}$ & $\begin{array}{l}\text { Case } \\
\text { No }\end{array}$ & Sex & $\begin{array}{l}\text { Specimen } \\
\text { type }\end{array}$ & $\begin{array}{l}\text { Age } \\
(y)\end{array}$ & $\begin{array}{l}A W U V \\
\left(\mathrm{~mm}^{2} / \mathrm{mm}^{3}\right)\end{array}$ \\
\hline $\begin{array}{l}1 \\
2 \\
3 \\
4 \\
5 \\
6 \\
7 \\
8 \\
9 \\
10 \\
11 \\
12 \\
13 \\
14 \\
15 \\
16\end{array}$ & $\begin{array}{l}F \\
F \\
F \\
F \\
F \\
F \\
M \\
F \\
M \\
F \\
F \\
F \\
F \\
F \\
F \\
F\end{array}$ & $\begin{array}{l}\text { RL } \\
L L \\
R L \\
L L \\
L L \\
L L \\
L L \\
L L \\
L L \\
L L \\
R L \\
L L \\
L L \\
L L \\
L L \\
L L\end{array}$ & $\begin{array}{l}22 \\
22 \\
23 \\
52 \\
57 \\
70 \\
74 \\
75 \\
77 \\
79 \\
82 \\
82 \\
83 \\
83 \\
84 \\
93\end{array}$ & $\begin{array}{l}20 \cdot 38 \\
19.43 \\
21.90 \\
18 \cdot 62 \\
20 \cdot 13 \\
16.32 \\
14 \cdot 27 \\
14 \cdot 02 \\
16.33 \\
16.09 \\
15.04 \\
15 \cdot 88 \\
18 \cdot 24 \\
12.03 \\
14 \cdot 10 \\
15.33\end{array}$ & $\begin{array}{l}1 \\
2 \\
3 \\
4 \\
5 \\
6 \\
7 \\
8 \\
9 \\
10 \\
11 \\
12 \\
13 \\
14 \\
15 \\
16 \\
17 \\
18 \\
19 \\
20 \\
21 \\
22\end{array}$ & $\begin{array}{l}M \\
M \\
M \\
M \\
F \\
M \\
M \\
F \\
F \\
F \\
F \\
M \\
M \\
M \\
M \\
M \\
M \\
F \\
F \\
F \\
F \\
M\end{array}$ & $\begin{array}{l}\text { RUL } \\
\text { LUL } \\
\text { RLL } \\
\text { LLL } \\
\text { LLL } \\
\text { LLL } \\
\text { RUL } \\
\text { RLL } \\
\text { LLL } \\
\text { LUL } \\
\text { LLL } \\
\text { RUL } \\
\text { RUL } \\
\text { RLL } \\
\text { RUL } \\
\text { RUL } \\
\text { LLL } \\
\text { LUL } \\
\text { LLL } \\
\text { LLL } \\
\text { RUL } \\
\text { RUL }\end{array}$ & $\begin{array}{l}21 \\
23 \\
23 \\
28 \\
30 \\
31 \\
32 \\
48 \\
49 \\
49 \\
50 \\
52 \\
53 \\
54 \\
56 \\
56 \\
58 \\
63 \\
64 \\
66 \\
69 \\
78\end{array}$ & $\begin{array}{l}21 \cdot 75 \\
21 \cdot 98 \\
21 \cdot 58 \\
20 \cdot 69 \\
18 \cdot 86 \\
22 \cdot 34 \\
19 \cdot 73 \\
16 \cdot 68 \\
18 \cdot 90 \\
18 \cdot 27 \\
16 \cdot 87 \\
20 \cdot 51 \\
17 \cdot 38 \\
17 \cdot 06 \\
18 \cdot 38 \\
15.99 \\
16.90 \\
17 \cdot 30 \\
17 \cdot 03 \\
19 \cdot 55 \\
19 \cdot 15 \\
18 \cdot 30\end{array}$ \\
\hline
\end{tabular}

RL—right lung; LL—left lung; RUL—right upper lobe; RLL—right lower lobe; LUL-left upper lobe; LLL—left lower lobe.

size. ${ }^{28}$ We recently measured airspace size in terms of AWUV in sections from fixed and inflated human lungs and found that, in the absence of severe macroscopic emphysema, there was no significant apex to base variation in AWUV within individual lobes and no significant differences in mean AWUV between the upper and the lower lobes. ${ }^{20} \mathrm{We}$ are satisfied therefore that in these non-smokers the AWUV pattern of a single lobe reflects that of the entire lung. This is in general agreement with previous studies, where non-quantitative assessments of emphysema from two different lobes of lungs from the same subject generally showed similar degrees of change. ${ }^{29} 30$ Auerbach and coworkers ${ }^{29}$ found that rupture of alveolar walls occurred to a similar degree in right and left lungs and in the upper and the lower lobes of these lungs. More recently, Wright and colleagues ${ }^{30}$ noted that the upper and lower lobes of their series of lungs obtained at surgery had similar grades of macroscopic emphysema as assessed by the panel grading system of Thurlbeck et al. ${ }^{4}$

\section{AWUV-AGE RELATIONSHIP}

We found in this study that AWUV measurements were reduced by about $30 \%$ between the ages of 21 and 93 years, and that this decrease in AWUV was linear. These results imply that the average airspace size increases with advancing age. Thurlbeck also found a linear change in airspace size with age in his study of mean linear intercept measurements in macroscopically non-emphysematous lungs. ${ }^{31}$ Unfortunately, however, the smoking histories of his subjects were not recorded.

The individuals studied here were lifelong non-smokers from urban and rural areas. Their only known pulmonary abnormality was the small peripheral lesion for which thoracotomy was carried out in the surgical cases. We consider therefore that these individuals represent, as nearly as possible, a population with normal lung structure. We have used the $95 \%$ prediction limits for the regression of AWUV and age to define the limits of normality of AWUV in this sample.

The entity of senile emphysema has been described as the barely visible macroscopic abnormality of the lung in the elderly. ${ }^{32} \mathrm{We}$ might therefore have expected to find an increased rate of decrease in AWUV with advancing age after the onset of senile emphysema. As stated above, however, the decline in AWUV with advancing age in our sample was linear.

A Ciba report in $1959^{3}$ recommended that the term senile emphysema should not be used until "the normal range of size of air spaces in the lung at different ages has been established." We propose that the $95 \%$ prediction limits we have described should be used to identify a range of normal values of airspace surface area, and that microscopic emphysema may be defined as AWUV values below the lower prediction limit. This conforms to the definition of emphysema as abnormal enlargement of the airspaces distal to the terminal bronchiole.

We do not think that elderly patients with AWUV values within the $95 \%$ prediction limits for their age should be considered as having emphysema, even though their AWUV values are significantly lower than those of subjects in early adult life. This view is in keeping with the approach to tests of lung function, where the progressive decline in lung function from young adulthood with advancing age is accepted as normal. ${ }^{33}$ In future, clinical and pathological studies must take the age related change in normal values 
for AWUV into account before emphysema is diagnosed.

Gould et $a l^{21}$ reported on a structure-function study of the lung that included analysis of the results of computed tomography. A comparison of computed tomography and AWUV measurements made on the same lungs showed a linear relationship between density values from the computed tomogram and AWUV measurements. These results suggest that the changes of early emphysema might be recognisable on computed tomograms. If computed tomography is to be used in the diagnosis of emphysema it is essential that a range of normal computed tomographic densities according to age should be established. This is obviously an area that requires further study.

\section{SEX DIFFERENCES}

We found no sex differences in the relationship between AWUV and age in our sample of non-smokers. Differences in normal airspace size thus appear unlikely to be the basis of the published differences in the incidence of emphysema between the sexes.9-12 1517183435

THE USE OF THE TERM EMPHYSEMA

Small areas of macroscopic emphysema were found in lung specimens from three subjects whose mean AWUV measurements fell within the normal range. This result shows that small areas of emphysema, or focal lesions of the centriacinar type, which represent abnormally large airspaces in small areas of lung, do not affect the overall mean AWUV values. These are best described as focal, or localised, macroscopic emphysema. The term emphysema should not be used without qualification-rather the type and severity of the observed lesions should be described. We suggest that a patient, or a lung, should not be considered as having "emphysema" unless this refers to microscopically assessed emphysema with a mean AWUV value outside the $95 \%$ prediction limits for the population, which would thus take into account the age related changes in airspace size described here.

We thank ASJ Farrow and $M$ Stark for the programming and maintenance of the fast interval processor and $L$ Norrie for technical assistance. This study was funded by the Norman Salvesen Emphysema Research Fund.

1 Snider GL, Kleinerman J, Thurlbeck WM. The definition of emphysema. Report of a National Heart Lung and Blood Institute, division of lung diseases, Workshop. Blood Institute, division of lung
Am Rev Respir Dis 1985;132:182-5.

2 Anderson WF, Anderson AE, Hernandez JA, Foraker AG Topography of aging and emphysematous lungs. $A m$ Rev Respir Dis 1964;90:411-23.

3 Ciba. Terminology, definitions and classification of chronic pulmonary emphysema and related conditions. Report of the conclusions of a Ciba Guest Symposium Thorax 1959;14:286-99.

4 Thurlbeck WM, Dunnill MS, Hartung W, Heard BE Heppleston AG, Ryder RC. A comparison of three methods of measuring emphysema. Hum Pathol $1970 ; 1: 215-26$
5 Dunnill MS. Quantitative methods in the study of pulmonary pathology. Thorax 1962;17:320-8.

6 Ryder RC, Thurlbeck WM, Gough J. A study of interobserver variation in the assessment of the amount of pulmonary emphysema in paper-mounted whole lung sections. Am Rev Respir Dis 1969;99:354-64.

7 Weibel ER. Morphometry of the human lung. Berlin: Springer, 1963:56-73.

8 Schreider JP, Raabe OG. Structure of the human respiratory acinus. Am $\mathcal{F}$ Anat 1981;162:221-32.

9 Dunnill MS. Pulmonary pathology. 2nd ed. Edinburgh: Churchill Livingstone, 1987;97-132.

10 Sobonya RE, Burrows B. The epidemiology of emphysema. Clin Chest Med 1983;4(3):351-8.

11 Dijkman JH. Morphological aspects, classification and epidemiology of emphysema. Bull Eur Physiopathol Respir 1986;22:241-3S

12 Snider GL. Chronic obstructive pulmonary disease: risk factors, pathophysiology and pathogenesis. Annu Rev Med 1989;40:411-29.

13 Anderson AE, Hernandez JA, Holmes WL, Foraker AG. Pulmonary emphysema. Prevalence, severity and anatomical patterns in macrosections, with respect to smoking habits. Arch Environ Health 1966;12:569-77.

14 Ryder R, Dunnill MS, Anderson JA. A quantitative study of bronchial mucous gland volume, emphysema and smoking in a necropsy population. $f$ Pathol 1971;104:59-71.

15 Anderson JA, Dunnill MS, Ryder RC. Dependence of the incidence of emphysema on smoking history age and sex. Thorax 1972;27:547-51.

16 Spain DM, Siegel H, Bradess VA. Emphysema in apparently healthy adults. Smoking, age and sex. $\mathscr{f} A M A$ 1973;224:322-5.

17 Thurlbeck WM, Ryder RC, Sternby N. A comparative study of the severity of emphysema in necropsy populations in three different countries. Am Rev Respir Dis 1974;109:239-48.

18 Sutinen S, Vaajalahti P, Paako P. Prevalence, severity and types of pulmonary emphysema in a population of deaths in a Finnish city. Correltion with age, sex and smoking. Scand $\mathcal{F}$ Respir Dis 1978;59:101-15.

19 Adesina AM, Vallyathan V, McQuillen EN, Weaver SO, Craighead JE. Bronchiolar inflammation and fibrosis associated with smoking: a morphologic cross-sectional population analysis. Am Rev Respir Dis 1991;143:144-9.

20 Lamb D, Gillooly M, Farrow ASJ. Microscopic emphyse$\mathrm{ma}$ and its variations with age, smoking and site within the lung. Ann NY Acad Sci 1991;624:339-41.

21 Gould GA, MacNee W, McLean A, Warren PM, Redpath A, Best JJK, et al. CT measurements of lung density in life can quantitate distal airspace enlargement--an essential defining feature of human emphysema. $\mathrm{Am}$ Rev Respir Dis 1988;137:380-92.

22 Shippey GA, Bayley RJH, Farrow ASJ, Rutovitz DR, Tucker JH. A fast interval processor. Pattern Recognition 1981;14:345-65.

23 Gillooly M, Lamb D, Farrow ASJ. A new automated technique for the assessment of emphysema on histological sections. f Clin Pathol 1991;44:1007-11.

24 Ryan BF, Joiner BL, Ryan TA. Minitab Handbook. 2nd ed. Boston: Duxbury Press, 1985;218-35.

25 SPSS. SPSS- $X$ Users' Guide. 3rd ed. Chicago: SPSS Inc, 1988:849-70.

26 McLean A, Lamb D. Morphometry of small airways in man. F Pathol 1983;141:520.

27 West JB. Distribution of mechanical stress in the lung, a possible factor in localisation of pulmonary disease. Lancet 1971;1:839-41.

28 Glazier JB, Hughes JMB, Maloney JE, West JB. Vertical gradient of alveolar size in lungs of dogs frozen intact. $\mathcal{F}$ Appl Physiol 1967;23:694-705.

29 Auerbach O, Stout AP, Hammond AC, Garfinkel L. Smoking habits and age in relation to pulmonary changes. N Engl f Med 1963;269:1045-54.

30 Wright JL, Wiggs B, Pare PD, Hogg JC. Ranking the severity of emphysema on whole lung slices. Concordance of upper lobe, lower lobe and entire lung ranks. Am Rev Respir Dis 1986;133:930-1.

31 Thurlbeck WM. The internal surface area of non-emphysematous lungs. Am Rev Respir Dis 1967;95:765-73.

32 Reid L. The pathology of emphysema. London: LloydLuke, 1967:22-8.

33 Cotes JE. Lung function: assessment and application in medicine. 4th ed. Oxford: Blackwell, 1979:361-87.

34 Azcuy A, Anderson AE, Foraker AG. The morphological spectrum of aging and emphysematous lungs. An Intern Med 1962;57:1-17.

35 Auerbach O, Garfinkel L, Hammond EC. Relation of smoking and age to findings in lung parenchyma: microscopic study. Chest 1974;65:29-35. 